\title{
Is routine endoanal ultrasound useful in anal fistulas?
}

\author{
I. Pascual Migueláñez, D. García-Olmo, M. C. Martínez-Puente ${ }^{1}$ and J. A. Pascual Montero ${ }^{1}$

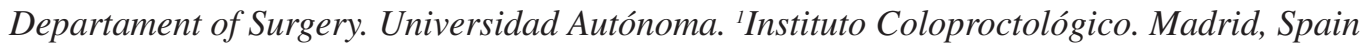

\begin{abstract}
Objective: to evaluate the effectiveness of endoanal ultrasound with hydrogen peroxide enhancement in the assessment of anal fistula (tract and internal opening), and to value the utility of this examination for anal or perianal suppuration when performed by a colorectal surgeon trained in this technique.

Patients: endoanal ultrasound was performed in 103 patients with anal or perianal suppuration. Twenty patients were excluded: 9 had the external opening closed, and 11 had cryptoglandular abscesses. All ultrasound scans were performed by the same explorer using a B\&K Diagnostic Ultrasound System with a $7 \mathrm{MHz}$ endoprobe. The examination was based on the identification of the three anal planes, then hydrogen peroxide was infused and the procedure was repeated.

Results: out of 83 patients included, 11 had a perianal sinus and 72 an anal fistula. In all fistulas the main tract was found: 24 were inter-sphinteric (33.33\%), 33 trans-sphincteric (45.83\%), 3 supra-sphincteric (4.17\%), and 12 extra-sphincteric (16.67\%). An internal opening was identified in 69 (95.83\%).

Conclusions: endoanal ultrasound with hydrogen peroxide enhancement is an effective examination to visualize fistulous tracts and internal openings. We think it is highly useful for anal or perianal suppuration to identify abscesses, to recognize a perianal sinus, to check the sphincteric condition, and to plan subsequent surgery.
\end{abstract}

Key words: Anal fistula. Endoanal ultrasonography. Hydrogen peroxide.

Pascual Migueláñez I, García-Olmo D, Martínez-Puente MC, Pascual Montero JA. Is routine endoanal ultrasound useful in anal fistulas? Rev Esp Enferm Dig 2005; 97: 323-327.

Recibido: 26-07-04.

Aceptado: 21-12-05.

Correspondencia: Isabel Pascual Migueláñez. C/ Costa Brava n³9. 2A 28034 Madrid. e-mail: isabelpasmi@hotmail.com.

\section{INTRODUCTION}

Surgical treatment of cryptoglandular fistula-in-ano represents even today a challenge for surgeons. The reason is double, as the goal of surgery not only is definitive fistula healing but also to avoid sphincteric damage, which can lead to continence disturbances. Fistulous tracts are untimely related with the sphincter, and acting in a definitive way on the fistula to prevent recurrences without anatomy changes is not an easy task. Parks classification (1), which classifies fistulas according to the relation between sphincters, internal and external, and the tract communicating the rectum with the perineal skin, is widely used. Four types of fistula can be distinguished: inter-sphincteric, transsphinteric, supra-sphinteric and extra-sphinteric. Any information available before surgery regarding fistula type (main tract trajectory, presence or absence of horse-shoe secondary tracts, presence of surgical changes in already operated on fistulas or in case of previous surgery nearby, etc.) may help the surgeon to plan surgery on a personal way. Knowing the place of the internal opening is particularly useful, which represents -according to Parks' theory- the origin of fistulas due to anal gland infection.

The purpose is to evaluate the effectiveness of endoanal ultrasounds -with hydrogen peroxide injected through the external opening-in the assessment of the tract and internal opening of anal fistulas as performed by a colorectal surgeon trained in this technique. The convenience of practising this exploration routinely for anal or perianal suppuration is also considered.

\section{PATIENTS AND METHOD}

Endoanal ultrasonographies were performed between March 2000 and February 2004 in 103 patients who consulted for anal or perianal suppuration in whom a 
cryptoglandular fistula-in-ano was suspected. Before each exploration the patient was briefed on the test and asked for consent.

Twenty patients were excluded of the study because no external opening could be identified to allow enhancement with hydrogen peroxide. Nine of them were established fistulas with a closed external opening at the time of the procedure, and eleven were abscesses of cryptoglandular origin that drained into the anal canal and had no tract to the perineal skin.

All ultrasound scans were performed by the same explorer using a B\&K Diagnostic Ultrasound System with a $7 \mathrm{MHz}$ endoprobe providing $360^{\circ}$ images.

Explorations were initiated with the introduction of the transducer and then a delicate withdrawal for the identification of the three ultrasound planes (upper, medium and lower). Immediately after, if an external opening was open at this moment, hydrogen peroxide was injected with a catheter and the exploration was repeated. The following information was collected for each patient: sphincteric damage (if any), location of external opening (quadrant and distance to the anus), type of fistulous tract according to Parks' classification (1) including any secondary tracts if present, and location of internal opening (quadrant and height: upper, medium or lower anal canal).

\section{RESULTS}

Among 83 patients included, no internal opening was identified in 11 cases when an endoanal ultrasound with hydrogen peroxide enhancement was performed. Furthermore, in these cases the enhanced tracts did not reach the sphincters. Therefore, they were labelled as a perianal sinus. Eight patients showed a posterior external opening, and three showed an anterior one. During physical examination, it was noticed that almost all of them had pilonidal sinus semiology.

In 72 remaining cases a tract in relation with the sphincters was clearly identified, and these were classified as true perianal fistulas.

Among these 72 fistulas, a fistulous main tract was found in $100 \%$ cases, with $24(33.33 \%)$ inter-sphincteric, $33(45.83 \%)$ trans-sphincteric, $3(4.17 \%)$ suprasphincteric, and 12 (16.67\%) extra-sphincteric cases being identified. In 5 cases secondary horseshoe tracts were identified (Fig. 1), and multiple tracts were found in 2. An internal opening was identified in 69 fistulas (95.83\%), with 37 being anterior and 32 posterior. It was located in the medium anal canal in 45 cases and in the upper anal canal in 24 (Fig. 2). Of the three fistulas in which no internal opening was identified, two had multiple secondary tracts (one of them was a case of Crohn's perianal disease), so the examination was more difficult.

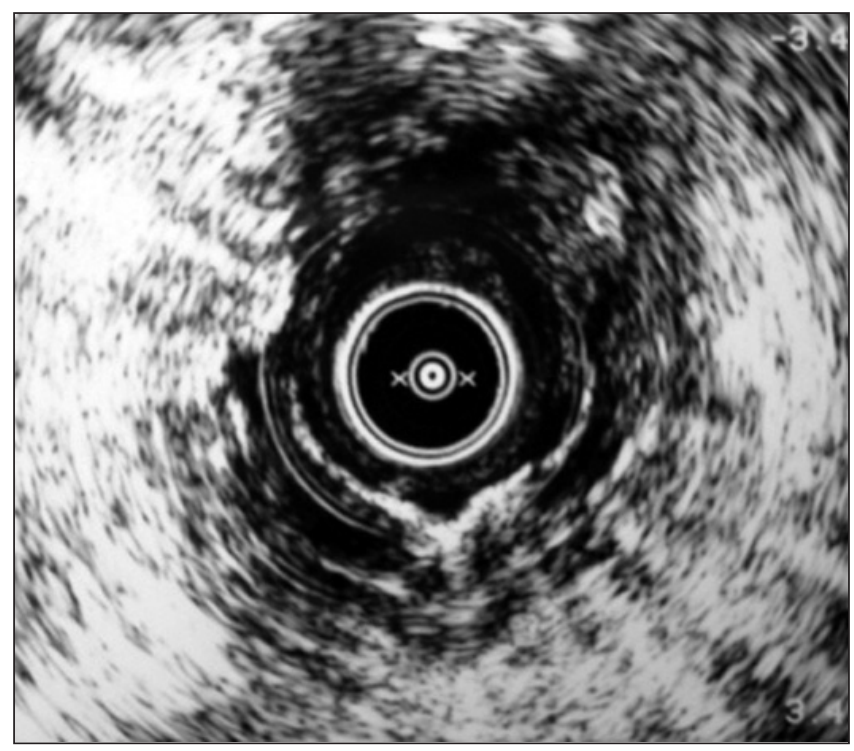

Fig. 1.- Posterior horseshoe tract. Trayecto en herradura posterior.

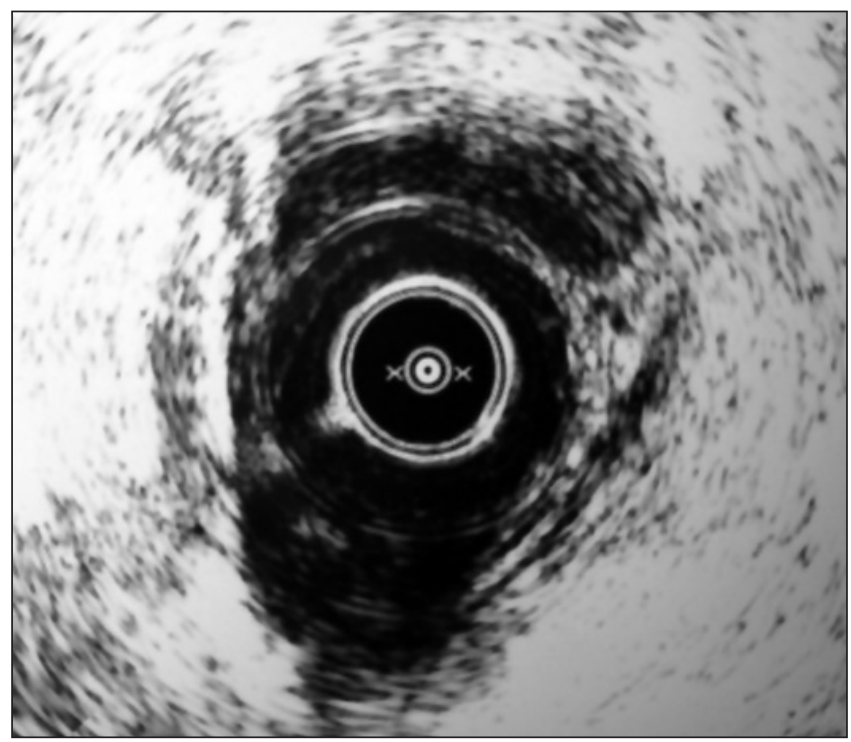

Fig. 2.- Internal opening in the upper anal canal. Orificio interno en canal anal alto.

Internal openings and surgical sphincteric changes were found in five fistulas that had been previously operated.

\section{DISCUSSION}

In perianal fistula, surgery knowing where the internal opening, if any, is located is essential, as is the map of the fistulous tract (2-6). Some methods have been 
used to this end: fistulography, magnetic resonance imaging, CT, and endoanal ultrasound scanning (7-12). Ultrasound scanning with hydrogen peroxide enhancement is a scarcely invasive, easy to perform and low cost test when compared to other methods. At this point, it is questioned if it should be performed routinely before surgery for perianal suppuration.

Our results indicate that about $20 \%$ of patients undergoing ultrasonography had no external opening, so hydrogen peroxide enhancement was impossible, as was to definitely establish the internal opening or tract map. Nevertheless, in these cases it is possible to correctly inform about perianal abscesses.

Even when the external opening is open, some authors have reported a low yield of endoanal ultrasounds to find an internal opening, identifying it in 48$60 \%$ of fistulas $(3,4)$. However, we could define it in more than $95 \%$ of patients when the external opening was open and the tract was related to the sphincters despite this being a biased series with a high number of specially complex fistulas (16.67\% extra-sphincteric); it is still thought that only complex fistulas should be studied using ultrasounds (6). In our opinion, this high level of definite location of internal openings could be due to the explorer, who was always a general surgeon specialized in coloproctology and trained in this technique.

As we have seen, it also informs about fistulous tracts and about the sphincters' condition. This is especially important when it is a recurrent fistula. No doubt, surgery of a mapped fistula will have a greater chance of success without complications (13).

It is also important to comment that in $10 \%$ of cases referred because of perianal suppuration with an external suppurative opening no tracts were found in relation with the sphincters. There were cases of pilonidal sinus semiology. Probably we face the fact that many times pilonidal disease reminds perianal fistula (1416). Some authors have reported $15 \%$ of sinuses in similar studies (6). In our opinion, this gives more value to endoanal ultrasound before surgery, as during surgery we can avoid useless and dangerous manipulations of the sphincters when trying to find a non-existant communication (13).

With our results -and other recent publications (2) about this topic with similar results- we think endoanal ultrasound with hydrogen peroxide enhancement, performed by a colorectal expert, is very useful for the surgery of both simple and complex fistulas. If performed in all cases of perianal suppuration, it may help decrease recurrence, since it facilitates the finding of internal openings during surgery, and this is a factor that has been associated with recurrence. Moreover, fistulous recurrence is a risk factor of new recurrence and anal incontinence (17). On the other hand, it may avoid unnecessary surgery in the search of an eventually non-existant internal opening.

\section{REFERENCES}

1. Parks AG, Gordon PH, Hardcastle JD. A classification of fistulain-ano. Br J Surg 1976; 63: 1-12.

2. Navarro-Luna, García-Domingo MI, Rius-Macias J, Marco-Molina C. Ultrasound study of anal fistulas with hydrogen peroxide enhancement. Dis Colon Rectum 2004; 47 (1): 108-14.

3. Poen AC, Felt-Bersma RJ, Eijsbouts QA, Cuesta MA, Meuwissen SG. Hydrogen peroxide-enhanced transanal ultrasound in the assessment of fistula-in-ano. Dis Colon Rectum 1998; 41 (9): 1147 52.

4. Ortiz H, Marzo J, Armendáriz P, Jiménez G. Valor de la ecografía endoanal con inyección de agua oxigenada en el diagnóstico de las fístulas perianales. Cir Esp 2002; 72 (6): 315-7.

5. Ortiz H, Marzo J, Jiménez G, De Miguel M. Accuracy of hydrogen-enhanced ultrasound in the identification of internal openings of anal fistulas. Colorectal Dis 2002; 4 (4): 280-3.

6. Sloots CE, Felt-Bersma RJ, Poen AC, Cuesta MA. Assessment and classification of never operated and recurrent cryptoglandular fistulas-in-ano using hydrogen peroxide enhanced transanal ultrasound. Colorectal Dis 2001; 3 (6): 422-6.

7. García Olmo D, Usero Rebollo S, Cifuentes Tebar J, Cascales Sánchez P, López Fando J. Recognition of internal openings in perianal fistulas. A comparison of three procedures. Dig Surg 1995; 12: 245-6.

8. Buchanan GN, Halligan S, Williams AB, Cohen CR, Tarroni D, Phillips RK, et al. Magnetic resonance imaging for primary fistula in ano. Br J Surg 2003; 90 (7): 877-81.

9. Bartram C, Buchanan G. Imaging anal fistula. Radiol Clin North Am 2003; 41 (2): 443-57.

10. Schaefer O, Lohrmann C, Langer M. Assessment of anal fistulas with high-resolution subtraction MR-fistulography: comparison with surgical findings. J Magn Reson Imaging 2004; 19 (1): 91-8.

11. García Montes JM, Caunedo Álvarez A, Herrerías Gutiérrez JM. Utility of the endo-rectal ultrasonography with sectorial transducer in the study of rectoanal pathology. Rev Esp Enferm Dig 2001: 93 (8): 509-18.

12. Ortiz H, Martí Ragué J, Chocarro C, de Miguel M. Fístulas perianales. En: Martí-Ragué J, Lledó S, Ortiz H. Actualización en Patología Anorrectal. Barcelona: Ed. J.R. Prous Editores, 1992. p. 111-31.

13. Malouf AJ, Buchanan GN, Carapeti EA, Rao S, Guy RJ, Westcott E, et al. A prospective audit of fistula-in-ano at St. Mark's hospital. Colorectal Dis 2002; 4 (1): 13-9.

14. García Olmo D, Jiménez Romero C. Sinus pilonidal. En: MartíRagué J, Lledó S, Ortiz H. Actualización en Patología Anorrectal. Barcelona: Ed. J.R. Prous Editores, 1992. p. 133-54.

15. Taylor SA, Halligan S, Bartram CI. Pilonidal sinus disease: MR imaging distinction from fistula in ano. Radiology 2003; 226 (3): 662-7.

16. Vallance S. Pilonidal fistulas mimicking fistulas-in-ano. Br J Surg 1982; 69 (3): 161-2.

17. García-Aguilar J, Belmonte C, Wong WD, Goldberg SM, Maddoff RD. Anal fistula surgery. Factor associated with recurrence and incontinence. Dis Colon Rectum 1996; 39 (7): 723-9. 